\title{
OPTIMALISASI PENDIDIKAN ANAK USIA DINI BERDASARKAN PEMBELAJARAN YANG BERBASIS PERKEMBANGAN OTAK
}

\author{
Nopika Dwi Arofah ${ }^{1}$, Siti Raf'ah Azizah', ${ }^{2}$ Agus Sumitra $^{3}$ \\ IKIP Siliwangi, Jl. Terusan Jenderal Sudirman Cimahi \\ ${ }^{2}$ IKIP Siliwangi, Jl. Terusan Jenderal Sudirman Cimahi \\ ${ }^{3}$ IKIP Siliwangi, Jl. Terusan Jenderal Sudirman Cimahi \\ 1‥arofah21@ gmail.com, ${ }^{2}$ sitirafah31@gmail.com, ${ }^{3}$ delaguspiero@gmail.com
}

\begin{abstract}
Brain-based learning is a comprehensive approach to instruction based on how current neuro-science research shows our brains learn naturally, that brain-based learning is a learning approach that emphasizes the best natural principles available in the operation of the brain, with the aim of achieving maximum attention, understanding, meaning, and memory. These base learning begins with what is known about the actual structure and use of human thought at various stages of development. Based on the previous explanation, the research conducted by Hazhira Qudsyi (please include the year and write in the bibliography) concludes about learning strategies that can optimize education in early childhood, namely through brain-based learning, because early childhood education (PAUD) is a very basic and strategic education, as the initial foundation for the growth and development of the next child. This research was conducted with qualitative research methods to understand the phenomenon. Based on these results, it was found that optimizing the learning process in early childhood education has its own challenges, especially with the typical characteristics possessed by students, namely early childhood. This article was written with the aim of studying brain-based learning as an effort to optimize early childhood education.
\end{abstract}

Keywords: Early Childhood Education, Brain Development

\begin{abstract}
Abstrak
Pembelajaran berbasis otak (brain-based learning) adalah pendekatan komprehensif untuk instruksi yang didasarkan pada bagaimana penelitian terkini pada neuro-science menunjukkan otak kita belajar secara alami,bahwa brain-based learning adalah sebuah pendekatan pembelajaran yang menekankan pada prinsip-prinsip alami terbaik yang ada pada operasional otak, dengan tujuannya untuk mencapai perhatian (atensi) yang maksimum, pemahaman, pemaknaan, dan ingatan.Brain-base learning ini dimulakandengan apa yang diketahui tentang struktur aktual dan guna pemikiran manusia pada berbagai tahap perkembangan. Berdasarkan pemaparan sebelumnya, penelitian yang dilakukan oleh Hazhira Qudsyi(tolong cantumkan tahun dan tuliskan di daftar pustaka) menyimpulkan mengenai strategi pembelajaran yang dapat mengoptimalkan pendidikan pada anak usia dini, yakni melalui pembelajaran berbasis otak (brain-based learning), karena Pendidikan anak usia dini (PAUD) merupakan pendidikan yang amat mendasar dan strategis, sebagai fondasi awal bagi pertumbuhan dan perkembangan anak selanjutnya. Penelitian ini dilakukan dengan metode penelitian kualitatif untuk memahami fenomena tersebut. Berdasarkan hasil tersebut, diperoleh hasil bahwa mengoptimalkan proses pembelajaran pada pendidikan anak usia dini memiliki tantangan tersendiri, terlebih dengan karakteristik khas yang dimiliki oleh peserta didik, yakni anak usia dini. Artikel ini ditulis dengan tujuan untuk mengkaji proses pembelajaran berbasis pengembangan otak (brain-based learning) sebagai salah satu upaya untuk mengoptimalkan pendidikan anak usia dini.
\end{abstract}

Kata Kunci $\quad$ : Pendidikan Anak Usia Dini, Perkembangan

How to Cite: Arofah, N.D., Azizah, S.R., \& Sumitra, A. (2019). OPTIMALISASI PENDIDIKAN ANAK USIA DINI BERDASARKAN PEMBELAJARAN YANG BERBASIS PERKEMBANGAN OTAK. Ceria, 2 (2), 7-14. 


\section{PENDAHULUAN}

Pada masa usia golden age ini banyak terjadi proses nilai kehidupan yang pertama kali.Masa anak-anak adalah suatu masa yang relative panjang untuk anak dalam belajar tentang segala hal. Pada masa ini anak mengalami proses perkembangan dalam beberapa problem, seperti perkembangan fisik, kemampuan akademik, kemampuan mental, perkembangan sosial, perkembangan emosional, maupun perkembangan moral. Anak memiliki banyak kemampuan pada tiap ragam perkembangan tersebut.

Pendidikan anak usia dini (PAUD) ialahlembaga pendidikan yang dapat memberikananak dalam mengoptimalkan potensi perkembangan yang ada pada dirinya, yaitu pada AUD. Suyanto (2005) menjelaskan bahwa PAUD bertujuan untuk mengembangkan potensi anak (the whole child)agar kelak dapat berfungsi sebagai manusia yang utuh sesuai falsafah bangsa. Hal ini penting sekali untuk dikaji karena PAUD merupakan hal paling dasar dalam pembelajaran seorang anak, dengan kata lain pada masa inilah anak-anak mulai mengalami proses perkembangan dalam berbagi hal, seperti fisik, kognitif, mental sosial, emosional maupun perkembangan moral.

Demikian juga pembelajaran diberikan harus sesuai dengan sifat anak. Pembelajaran PAUD yang dapat dilakukan menggunakan pembelajaran ini (brain-based learning). Artikel ini ditulis untuk mengkaji proses pembelajaran berbasis pengembangan otak (brain-based learning) sebagai upaya untuk mengembangkan pendidikan anak usia dini.

\section{KAJIAN TEORI}

\section{Perkembangan Usia Pra Sekolah}

Menurut Santrock (2002), masa anakanak ada di2 tingkat dalam perkembangan manusia, yaitu awal anak-anak (early childhood) yang merupakan periode perkembangan dari masa bayi hingga usia kuranglebih lima atau enam tahun, atau kadang-kadang disebut sebagai "tahun-tahun pra sekolah", dan pada masa pertengahan dan akhir anak- anak (middle andlate childhood) yang merupakan periode perkembangan dariusia kira-kira enam hingga 11tahun, atau sering disebut sebagai "tahuntahun sekolah dasar".

Berdasarkan pendapat yang telah dipaparkan bisadiambil kesimpulanbahwa usia anak sekolah merupakan sekumpulanumurdalam usia 0 tahun (lahir) sampai enam tahun, mengingat lagi karya tulis ini diutamakan pada pendidikan usia pra sekolah Indonesia, maka jarak usia yang dipakai adalah 0-6 tahun.

Perkembangan Kognitif

Piaget (dalam Atkins onetal., 1993), ada empat stadiumperkembangan kognitif yang terjadi masa anak-anak, yakni:

a. Stadium Sensori motorik (0-2tahun) Karakterisasi pada stadium ini adalah anak mampu mengenali diri sebagai pelaku tindakan dan bertindak sengaja, contohnya mengambil tali kendaraan. Selain itu, anakpun telah mencapai objek, yaitu sadar bahwa benda- benda terus ada walau tak tertangkap lagi oleh indera. Lebih jelas Piaget (dalam Santrock, 2002) menerangkan bahwa selama masa sensori motorik ini, perkembangan mental diberitanda oleh kemajuan yang besar dalam kemampuan bayi untuk mengorganisasikan dan mengkoordinasikan sensasimelalui gerakangerakan dan tindakan-tindakan fisik. Secara lebih akurat, pada tahapan ini, ada beberapa sub tahap perkembangan sensoris-motorik (Santrock, 2002; Papalia, Old,\&Feldman, 2008), yakni:

1. Refleks sederhana

2. Reaksi sirkuler primer

3. Reaksi sirkuler sekunder

4. Koordinasi reaksi sirkuler sekunder (koordinasi skema sekunder)

5. Reaksi sirkuler tersier

6. Kombinasi mental

b. Stadium Praoperasional (2-7tahun)

Karakterisasi pada tahapan iniyaitu anak telah belajar memakai bahasa dan mempraktekan objek dengan cerita dan katakata. Selain itu, anak masih punya pemikiran yang memikirkan diri sendiri, dimana anak 
inimengalami kesulitan dalam melihat dari sisi orang lain.

Pemikiran pra operasional dapat dibagi ke dalam dua sub tahap, yakni:

\section{1) Sub tahap fungsi simbolis}

Sub fase ini terjadi kurang lebih antara usia dua hingga empat tahun, dimana anak mengembangkan kemampuan untuk membayangkan secara real suatu obyek yang tidak ada. Pada tahapan inilah, terdapat ciri pemikiran yang kuat, ialah egosentrisme (Santrock, 2002).

\section{2) Sub tahap pemikiran intuitif}

Sub tahap kedua ini terjadi kira-kira antara usia empat dan tujuh tahun, dimana anak mulai menggunakan penalaran primitif dan ingin tahu jawaban semua pertanyaan. Piaget menyebut periode waktu ini "intuitif" karena anak-anak rupanya yakin akanpengetahuan dan pemahamannya tetapi belum sadar bagaimana mereka tahu atas apa yang mereka pahami itu. Maksudnya, mereka berkata mengetahui persoalan namun mengetahuinya tanpa memakaipemikiran konkret.

c. Stadium Operasional Konkret (7-11tahun)

Karakterisasi pada tahapini yaitu anak telah dapat berpikir secaralogis tentang objek dan peristiwa.

\section{d. Stadium Operasional Formal (11 tahun keatas)}

Karakterisasi pada tahap ini yaitu anak telahdapat berpikir secara logis mengenai masalah abstrak dan menguji hipotesis secara sistematik.

Berdasarkan pemaparan diatas, maka dapat diartikan bahwa perkembangan kognitif terjadi dimasa anak dibawah umur ialah pada tahapan perkembangan kognitif sensorimotorik dan tahap pra perasional.

\section{Perkembangan Sosial emosi}

Emosi ialahreaksi subjek terhadap persoalan yang diasosiasikan oleh perubahan kejiwaan dan tingkahlaku (Papalia, Old, \& Feldman, 2008). Anak mulai mengembangkan emosi dasarnya dimulai pada umur enam bulan, dimana emosi ini mencakup rasa gembira, marah, sedih, dan takut (Santrock,2002). Meskipun demikian, sejak bayi itu lahir, sudah dapatmenunjukkan emosinya dengan bentuk yang udah. Misalkan bayi menunjukkan rasa tidaknyamanseperti menangis yang mencengangkan telinga, menendang tangan dan kaki, serta mengejangkan tubuhnya(Papalia, Old,\&Feldman, 2008).

Erik Erikson (dalam Megawangiet al .2004) beranggapan bahwa perkembangan emosi baik sangat penting pada perkembangan kejiwaan anak. Menurut Erikson terdapat 8tahap perkembangan sosio emosi pada individu. Secara ringkas, pada tulisan ini akan dibahas pada tahapan perkembangan sosio emosi anak non formal, yakni:
a. Tahap trust vs mistrust (percaya vs tidakpercaya)
b. Tahap autonomy vs shamel doubt (kemandirianvs.malu/ragu)
c. Tahap initiative vs guilt (inisiatif vs. merasabersalah)
d. Tahap industry vs inferiority (berkarya/etos kerja vs minder)

\section{Perkembangan Moral}

Seperti yang telah diketahui, pada kehidupan ini sering terjadi pertanyaan mengenai perbuatan atau tindakan mana saja yang terkait dengan sesuatu yang tepat dan kurang tepat. Sering kali pertanyaan tersebut muncul baik sebelum tindakan itu dilakukan, saat dilakukan, maupun sesudah dilakukan. Perbuatan atau tindakan seperti apakah yang termasuk dalam perbuatan baik itu? Atau perbuatan seperti apakah yang termasuk dalam perbuatan buruk itu? Apakah yang sesuai dengan peraturan maka disebut perbuatan yang baik? Atau tingkah yang tepat menuju hati nurani seseorang baru dapat dikatakan perbuatan yang baik? Berbicara mengenai hal yang benar dan salah ini adalah berbicara mengenai moral.

Yang dijelaskan sebelumnya merupakan beberapa aspek perkembangan pada individu, terutama dalam konteksnya pada anak non formal. Aspek-aspek perkembangan inilah patut 


\section{JURNAL CERIA}

ISSN : 2614-6347 (Print) 2614-4107 (Online)

Vol.2 | No.2 | Maret 2019

menjadi bahan pemikiran bagi para penyelenggara pendidikan akan anak dibawah umur dalam menjaga pembelajaran bagi anak dini, sehingga tidak mengucilkan aspek alami yang sedang berkembang pada diri anak, termasuk nantinya adalah pada perkembangan otak anak dini yang akan dijelaskan kemudian.

\section{Perkembangan Otak Usia Dini}

Periode dari otak menyerap dibagi menjadi dua fase ,yaitu fase pertama dari usia satu hingga tiga tahun, ketika otak anak bertugas secara tak sadar dan pembelajaran dihasilkan dari interaksi dengan respon terhadap pengaruh lingkungan. Selama periode inilah, anak menuju merubah kepribadian dan kecerdasan mereka dengan aktivitasnya dalam menjaga lingkungan dan kesan yang mereka rasa selama aktivitas itu. Anakmulai memperoleh bahasa dan kebudayaannya darilingkungannya dimana mereka dilahirkan. Selama tingkat berikutnya, dari umur tiga tahun hingga enam tahun, sanganak telah sadar dan terarah pada aktivitas aktivitas mereka dalam mengekplorasi lingkungan. (dalam Sumitra, A. 2014).

Pertumbuhan otaksangat dibutuhkan dalam perkembangan fisik,kecerdasan,dan emosi pada individu (Papalia, Old, \& Feldman, 2008 ; Mutiah, 2010). Tidak diragukan lagi bahwa otakmerupakan pusat kecerdasan.

Ketika lahir,berat otak individu hanya sekitar $25 \%$ dari beratnya otak dewasa, dan pada tahun kedua, otak bayi yang baru lahir sekitar 75\% berat otak dewasa (Santrock, 2002; Papalia, Old, \& Feldman, 2008 ; Kledon, 2006). Pada usia enam tahun, ukuran otak hampir segede otak orang dewasa, namuntumbuh kembang fungsi bagian spesifik dari otak terus berlanjut sampai dewasa (Papalia, Old, \& Feldman, 2008).

Jumlah antar sel otak tersebut sangat ditentukan oleh rangsangan dan makanan. Memberi rangsang pada anak memakai fungsi inderanya perlu untuk pertumbuhan hubungan antarsel syaraf otak (Suyanto,2005).

Berdasarkan pemaparan yang telah dipaparkan diatas,dapat dipahami bahwa perkembangan otak menjadi acuan penting pada pengasuhan dan kembang anak dini karena seperti yang sudah dimengerti sebelumnya bahwa otak memiliki kendali pada kehidupan seorang manusia. Melalui otak, seseorang mengenal dunianya, mengetahui semua informasi dan pengalaman, baik yang sifatnya senang maupun sedih. Kledon (2006) menerangan bahwa saat paling menentukan bagi perkembangan otak itu pada umur 0-3 tahun. Sebagaimana yang dijelaskan pula oleh Papalia, Old, \& Feldman (2008) nyatanya pertumbuhan cepat otak yang diawalikira-kira pada bulan ketiga saat hamil dan berlanjut sampai paling tidak umur 4 tahun penting untuk fungsi syaraf.

\section{METODE PENELITIAN}

Model penelitian ini adalah metode penelitian kualitatif yaitu penelitian yang bermaksud untuk mengenal fenomena tentang apa yang dialami oleh subjek penelitian, misalnyaperilaku, persepsi, motivasi, tindakan dan lain-lain secara jolistik, dan dengan cara deskripsi dalam bentuk kata-kata dan bahasa, pada konteks khusus yang alamiah dan dengan memanfaatkan berbagai metode alamiah. Penelitian ini dilaksanakan pada dikelompok A RA Nurul Huda Sarijadi Bandung.

\section{PEMBAHASAN DAN HASIL HASIL}

Mencari ilmu pada usia pra sekolah mempunyai cara tersendiri. Seringterjadi guru dan wali muridmengenalkan anandasesuai jalan pikiran orang dewasa. Akibatnya, yang dikenalkanwali murid sulit diterima ananda. Untuk itu, menurut Suyanto (2005), wali murid dan guru anak pra sekolah perlu memahami pengertian perkembangan anak dan pengertian perkembangan anak dan pengertian Pendidikan Pra Sekolah agar dapat memberi pendidikan dengan jalan pikiran anak.

Belajar memang telah menjadi hal yang mudah. Ananda mempunyai kemauan dalam mengetahui, dan disanaada proses mencari ilmu pada anak. Samahalnya dengan yang dipaparkan 
oleh Kline (dalam Megawangi etal.,2004), bahwa belajar merupakan insting alami pada semua manusia semenjak manusia itu lahir. Anak kecil begitu tertarik dengan segala sesuatu yang ditemui disekitarnya. Melalui eksplorasi dengan melibatkan semua jenis inderanya. Selain itu, Pestalozzi (dalam Mutiah, 2010) pun berpendapat bahwa anak mencari ilmumenggunakan penelitian, dimana penelitian seorang anakakan membuat pengertian.

\subsection{Pembelajaran Berbasis Otak (Brain-BasedLearning)}

Spears \& Wilson (2000) memaparkan bahwa teori brain-based learning ini didasarkan pada apa yang kita ketahui tentang struktur aktual dan fungsi otak manusia dari berbagai fase perkembangan. Jenis pendidikan model seperti ini menyediakan kerangka biologis didorong untuk proses mengajar dan belajar, serta membantu menjelaskan perilaku belajar yang beru lang. Saat ini, teknik mengharuskan pada gimana para guru dapat menghubungkan cara belajar pada anak didik dengan pengalaman nyata peserta didik dalam kehidupannya.

Nuangchalerm \& Charnsirirattana (2010) menjelaskan bahwa perkembangan pengetahuan neurosaintifik mendorong manajemen belajar dari peneliti terutama pada ilmu pengetahuan di semua bidang. Hasil dari ini pengaruh neuroscience pada bidang pendidikan ialah dalam hal otak dan fungsinya ketika siswa belajar Hasil riset otak yang dilakukan oleh Paul McLean (dalam Megawangi et al., 2004; Syafa'at, 2007; Keles \& Cepni, 2006) menunjukkan bahwa ada 3 bagian otak yang mempunyai fungsi berbeda dalam mempengaruhi proses belajar tergantung pada bagian otak mana yang sedang memegang kendali. Ketiga otak ini adalah:

1. Batang otak (brainstem)

2. Cerebralcortex (otak intelektual)

3. Sistem Limbik (otak emosi)

Dengan demikian, dapat dipahami bahwa suasana emosi sangat menentukan efektifitas belajar pada anak sehingga pada akhirnya perlu untuk membuat suasana menjadi lebih menyenangkan bagi anak-anak biar proses belajar pada anak dapat berkembang lebih optimal.Joyce \& Weil (dalam Nuangchalerm \&Charnsirirattana, 2010) menjelaskan bahwa brain-based learning akan berfungsi di dalam kelas pada empat area, yakni tujuan, proses pembelajaran, penilaian (asesmen), dan sistem pendukung.

\section{Tujuan}

Pembelajaran berbasis otak memerlukan peserta didik untuk memiliki keseimbangan dari dua fungsi otak kiri dan kanan, peserta didik dapat membuka masalah mereka secara sistemik, belajar tentang pengetahuan, proses, dan sikap yang dimaksud. Selain itu, peserta didik dapat membangun, menghubungkan, menjelaskan, bertanya, dan berkomunikasi tentang apa yang diajari bersama orang lain dengan memakai teori multiple intelligences.

\section{Proses Belajar}

Metode ini dapat memberi sintaks instruksi kedalam lima langkah. PRADA-persiapan, relaksasi, tindakan, diskusi, dan aplikasi, yang digambar dalam bentuk sintaks model pembelajaran dengan contoh pelajaran sains berbasis otak. Preparation Aplication Relaxation partisipasi untuk menilai seperti self-asssessment atau peer-assessment yang mana hal tersebut seimbang bagi anak didik.

a. Peralatan asesmen pembelajaran: guru sudah menentukan alat asesmen pembelajaran berdasarkan situasi. Keanekaragaman alat dapat dipertimbangkan dan dievaluasi berdasarkan pengetahuan siswa, kinerja, dan perilaku serta sebagaimana fenomena yang dapat diamati.

b. Kriteria asesmen pembelajaran: kriteria harus dengan situasi konkret. Peserta didik harus mempunyai partisipasi pada penentuan idealis, hal itu akan membantu kedua asesor dan orang yang dinilai dapat diterima dalam suatu kriteria. 
3. Asesmen (penilaian)

a. Metode asesmen pembelajaran: para ilmuan mengungkapkan pengetahuan mereka pada metode asesmen pembelajaran yang membutuhkan sesuatu yang otentik, keragaman, dan keselarasan. Hal ini harus mencerminkan pengetahuan peserta didik, sikap, dan proses pada sains.

b. Media para ahli menunjukkan pendapat mereka tentang media pembelajaran yang memerlukan IT seperti internet, instruksi/pembelajaran berbasis web, dan sebagainya. Media harus ditampil-kan sebagai yang real, interatif, dan telah mempromosikan siswa agar mengekspresikan perasaan peserta, ide, dan sifat. Selain itu, media juga harus digunakan pada daerah lokal yang dapat membantu peserta didik untuk belajar berdasarkan pada perbedaan individu, kebutuhan, dan minat.

c. Lingkungan kelas: harus dibuat dan diciptakan dalam kondisi yang relaks. Muriddibawa untuk membuka jendela belajar mereka melalui pemikiran independen dan proses percakapan. Kelompok berita dan menyampaikangambar juga harus diijinkan, murid harus punyai waktu interaksi antara kelompok.

Sebagaimana yang telah diketahui pada awal bahwa seharusnya pola pendidikan pada aud harus dikembalikan pada kemampuan alami anak untuk belajar, yaitu oleh prinsip perkembangan serta kerjanya struktur dan fungsi otakanak. Segala proses pembelajaran yang dilakukan dalam pendidikan non formal atas semua bentuk stimulasinya harus berdasarkan oleh prinsip perkembangan dan bekerjanya struktur dan fungsi otak pada anak dini agar menjadi tujuan dari penyelenggaraan pendidikan non formal dapat tercapai efektif dan optimal.

\section{PEMBAHASAN}

Seperti yang sudah dikemukakan sebelumnya, bahwa agar pendidikan pada aud dapat berjalan optimal, tepat sasaran, dan sesuai dengan target dan tujuan, maka harus dapat dikembangkan strategi pembelajaran yang sesuai, seperti salah satunya adalah dengan pendekatan brain-based learning. Oleh karena itu, untuk mengoptimalkan pendidikan anakusiadini, pendidik dan orangtua harus dapat menyesuaikan dengan prinsip-prinsip yang ada pada pembelajaran berbasis otak. Berikut ini akan disampaikan beberapa upaya yang dilakukan oleh pendidik agar dapat mengoptimalkan pendidikan aud melalui pembelajaran berbasis otak (brain-based learning), yang patut sesuai dengan perkembangan anak (deve- lopmentally appropriate practices).

1. Menciptakan lingkungan belajar yang dapat membuat anak asyik dalam pengalaman belajar, yakni dengan melibatkan seluruh aspek fisiologis anak (Megawangi et al., 2004).

Dalam hal ini, Megawangi et al. (2004) mencontohkan, misalnya dalam belajar matematika, anak tidak tertarik dengan belajar duduk mengerjakan soal penambahan atau pengurangan, namun dengan permainan congklak yang intinya juga belajar penambahan dan pengurangan, anak akan lebih merasa senang belajar.

2. Menyediakan kesempatan belajar yang beragam dalam ruangan kelas.

Rushton, Juola-Rushton, \& Larkin (2010) memaparkan bahwa salah satu prinsip dasar lingkungan belajar yang mendukung stimulasi otak secara optimal adalah dengan menyediakan kesempatan belajar yang beragam dalam ruangan kelas, misalnya dengan adanya kawasan komputer, laboratorium pelatihan menulis, wilayah sains, material untuk bermain drama, dimana semua hal tersebut dapat memicu imajinasi dan stimulasi sensoris pada pembelajar anak-anak. Dengan konteks ini, anak belajar 
agar mengontrol pembelajaran mereka dan guru lebih berperan sebagai fasilitator.

Dengan istilah yang berbeda, penyediaan kesempatan belajar yang beragam dalam ruangan kelas juga dapat difasilitasi dalam pusat belajar (learning center). Dengan adanya pusat belajar, anak-anak dapat menyalurkan minatnya masing-masing, mencari tahu sesuatu yang memang mereka ingin tahu, dan dapat memfasilitasi potensi yang dimiliki oleh masing-masing anak (Suyanto, 2005). Sebagaimana kondisi ruangan kelas yang sudah dicontohkan dalam pendapat sebelumnya, di mana dalam ruangan kelas tersebut terdapat beberapa pusat belajar (learning center) yang dapat "memfasilitasi" potensi dan keunikan dari anak-anak. Ada anak yang ingin belajar memasak, ada anak yang ingin belajar melukis, ada anak yang ingin belajar menulis, dan sebagainya. Demikian pula dengan apa yang menjadi kesimpulan dari artikel ini, yakni perlu dibuatnya lingkungan belajar yang aktif dan merangsang bagi anak-anak, terutama bagi perkembangan jaringan neurologis dari otak anak, karena hal tersebut akan dapat meningkatkan kemampuan anak.

Sama halnya dengan anak-anak usia dini yang memiliki keunikannya masing-masing dalam belajar. Anak-anak lahir dengan membawa potensi dan keunikannya masing-masing. Keunikan ini juga akan membawa pada bagaimana mereka nantinya belajar atau berada dalam situasi pembelajaran.

3. Membuat lingkungan pembelajaran yang aktif.

Rushton, Juola-Rushton, \& Larkin (2010) menjelaskan bahwa terdapat beberapa komponen yang dibutuhkan dalam membuat lingkungan pembelajaran yang aktif, yakni:

a. Pengaturan fisik pada meja, kursi, pusat belajar, perpustakaan, pencahayaan, dan komponen lainnya yang dapat menarik minat anak;

b. Ruangan dirancang sedemikian rupa agar dapat digunakan untuk pekerjaan individu maupun pertemuan kelompok kecil dan besar;

c. Ketersediaan material manipulative dan ruang eksplorasi yang dapat menggugah rasa ingin tahu alami pada anak, sejumlah waktu yang banyak bagi anak untuk mengeksplorasi, bermain peran, dan bereksperimen.

d. Menciptakan kurikulum bisa menumbuhkan minat anak dan kontekstual, sehingga anak mampu menangkap makna atau arti dari apa yang dipelajarinya (Megawangi et al., 2004)

e. Memberikan pelajaran serta melibatkan pengalaman konkrit, terutama dalam pemecahan masalah karena proses belajar paling efektif bukan dengan ceramah, tetapi dengan diberikan pengalaman nyata (Megawangi etal., 2004).

\section{KESIMPULAN}

Berdasarkan penjrlasan sebelumnya, dapat disimpulkan tentang strategi pembelajaran yang dapat mengoptimalkan pendidikan aud, yakni melalui pembelajaran berbasis otak (brain-based learning) dengan prinsip-prinsip seperti di bawah ini:

1. Membuat lingkungan belajar yang dapat membuat anak asyik dalam pengalaman belajar, yaitu melibatkan semua aspek fisiologis anak

2. Menyediakan kesempatan belajar yang beragam dalam ruangan kelas

3. Membuat lingkungan pembelajaran yang aktif

4. Menciptakan kondisi belajar bebas tekanan dan ancaman namun tetapi menantang bagi anak agar mencari tahu lebih banyak

5. Menciptakan kurikulum yang dapat menumbuhkan minat anak dan kontekstual sehingga anak dapat menangkap makna atau arti dari apa yang dipelajarinya

6. Memberikan mata pelajaran dengan melibatkan pengalaman konkrit, terutama dalam pemecahan masalah, karena proses 


\section{JURNAL CERIA}

ISSN : 2614-6347 (Print) 2614-4107 (Online)

Vol.2 | No.2 | Maret 2019

belajar paling efektif bukan dengan ceramah, tetapi dengan diberikan pengalaman nyata

Yang sudah dikemukakan sebelumnya hanyalah beberapa prinsip yang dapat dijadikan pegangan dalam mengoptimakan pendidikan aud melalui pembelajaran berbasis otak. Meskipun demikian, pendidik masih dapat mengeksplorasi lagi hal-hal yang sekiranya dapat membuat pendidikan aud dapat berjalan secara optimal. Dengan catatan bahwa semua itu dilakukan harussesuai dengan tahapan perkembangan anak dan tidak mengesampingkan kebutuhan dasar dan alami pada anak.

\section{DAFTAR PUSTAKA}

Atkinson, et al. (1993). Pengantar Psikologi Jilid Satu, Edisi Kesebelas. Jilid Satu. Batam: Penerbit Interaksara.

Hurlock, E. B. (2002). Psikologi Perkembangan: Suatu Pendekatan Sepanjang Rentang Kehidupan. Jakarta: Penerbit Erlangga.

KeleŞ, E., \& Çepni, S. (2006). Brain and learning. Journal of Turkish Science Education, 3(2).

Kledon, T. (2006).Investasi itu bernama otak. Dalam Tim Penyusun. PAUD: Investasi

Megawangi, R. et al.. (2004). Pendidikan yang Patut dan Menyenangkan: Penerapan Teori Developmentally Appropriate Pracices (DAP) Anak-anak Usia Dini 0 sampai 8 tahun. Cimanggis: Indonesia Heritage Foundation.
Mutiah, D. (2010). Psikologi Bermain Anak Usia Dini. Jakarta: Kencana Prenada Media Group.

Nuangchalerm, P., \& Charnsirirattana, D. (2010). A delphi study on brain-based instructional model in science. Canadian Social Science, 6(4), 141-146.

Papalia, D., Old, S. W., \& Feldman, R. D. (2008). Human Development (Psikologi Perkembangan): Bagian I s/d Bagian I, Edisi Kesembilan. Jakarta: Kencana Prenada Media Group.

Rushton, S., Juola-Rushton, A., \& Larkin, E. (2010). Neuroscience, play, and early childhood education: Connections, implications, and assessment. Early Childhood Education Journal, 37, 351-361.

Santrock, J. W. (2002). Life-Span Development Perkembangan Masa Hidup, Edisi Kelima. Jakarta: Penerbit Erlangga.

Spears, A., \& Wilson, L. (2000). Brain-Based Learning Highlights. INDUS, Training and Research Institute.

Sumitra, A. (2014). PROSES PEMBELAJARAN BERBASIS METODE MONTESSORI DALAM MENGEMBANGKAN KETERAMPILAN SOSIAL ANAK USIA DINI (Penelitian Deskriptif Di PAUD Assya'idiyah Kab. Bandung Barat). Empowerment, 3(1), 60-70.

Suyanto, 2005. Konsep Dasar Anak Usia Dini : Jakarta : Departemen. Pendidikan Nasional. 